\title{
RADIO TELESCOPE AT JODRELL BANK EXPERIMENTAL STATION, UNIVERSITY OF MANCHESTER
}

$\mathrm{O}^{\mathrm{N}}$ $\mathrm{N}$ June 10, representatives of the Press and others assembled at the Jodrell Bank Experimental Station of the University of Manchester to inspect the progress on the erection of the radio telescope. The reasons for building the telescope, which is sponsored jointly by the Department of Scientific and Industrial Research and the Nuffield Foundation, were explained by Prof. A. C. B. Lovell, and the engineering consultant, Mr. H. C. Husband of Sheffield, described some of the engineering prob. lems. The essential feature of the telescope is a $250-\mathrm{ft}$. diameter steel bowl, paraboloidal in shape, $62 \cdot 5 \mathrm{ft}$. deep at the focus. This is to be covered with a reflecting screen of 1 inch square mesh. This main bowl, weighing 600 tons, will be carried on two towers so as to pivot on a horizontal axis $180 \mathrm{ft}$. above ground. The drive for the elevation movement will be by 100-h.p. metadyne motors through 27 -ft. tracks which were originally in the battleship Royal Sovereign. The two towers are each mounted on six bogies which move on a circular railway track. The bases of the towers are connected by a cross girder to the central pivot. The azimuth motion is obtained by an electrical drive from four of the bogies.

The foundations were completed by the end of 1953 . They consist of a concrete ring supported on reinforced piles sunk to the keuper marl (in places up to $90 \mathrm{ft}$. below ground-level), which carries the 17 -ft. gauge double railway track of diameter $350 \mathrm{ft}$. This railway track, which has to carry a superstructure weighing 1,500 tons, is level to $\frac{1}{8}$ inch, and in order to provide the necessary stability nearly 5,000 tons of steel and concrete have been used in the foundations. The central pivot, which is already in position, is carried on similar deep foundations. A sample of the twelve bogies on which the main steel framework is to be carried was also available for inspection. At the time of the visit, a $120-\mathrm{ft}$. crane mounted on $60-\mathrm{ft}$. gabbards was erecting the first of the main 15-ton 120 -ft. jib cranes on $120 \mathrm{ft}$. gabbards, two of which are required to erect the telescope itself. The erection of the steelwork is expected to begin this month and to be largely complete by the end of the year. It is anticipated that the radio telescope will be finished in 1955 .

The radio telescope was also discussed by Prof. Lovell in a Friday evening discourse at the Royal Institution on May 21. The need for such a large instrument arose from the desire to obtain high power gain and directivity in the investigation of the radio waves from space. In this the requirements are analogous to those of conventional telescopes. The significant advances in the study of the universe have been made through tho medium of large telescopes. Successive increases in aperture, culminating in the great 200-in. on Mt. Palomar, have given more resolving power and more light-gathering power, thereby enabling more distant regions of the universe to be explored. The analogy in radio astronomy is very close; but since the wave-lengths are a million times longer than light, the radio telescopes have to be of far greater size than their optical counterparts. Prof. Lovell described how the new radio telescope would be used for invostigating the extra-terrestrial sources of radio noise, or radio stars, so few of which have so far been identified with visible objects. Demonstrations were also given of the use of the radio telescope in the study of meteors, the moon, and of the complex relationships between events on the sun and the disturbances in the earth's ionosphere.

\section{METHODS OF LAND-CLEARANCE FOR AGRICULTURE}

$\mathrm{O}^{\mathrm{N}}$ $\mathrm{N}$ April 20 a meeting arranged by the Agriculture Group of the Society of Chemical Industry was held at the Royal College of Science, London, to discuss the large-scale clearing of forests. Unfortunately, three out of the five speakers named on the programme were unavoidably absent; the subject-matter of two papers, however (those of R. $H$. Gunn and A. MeBride), was incorporated by Dr. A. H. Bunting, of Tozi Research Farm, Singa, Sudan, into a joint paper entitled "A Review of Methods of Land Clearing".

Dr. Bunting began by pointing out that in many regions of the world land-clearing has always been $\mathrm{c}_{\mathrm{s}}$ fundamental component of agricultural systems and is an integral part of the system of shifting cultivation still widely employed by primitive communities who grow their crops on patches where the bush or forest has first been eut down or burnt. In many tropical areas the nutrient status of the soil is so low that, under the existing conditions of management, only one or two crops can be taken from the cleared area, which is then abandoned and soon becomes covered by vegetation consisting in the main of regrowth from the roots and stumps of the cut woody plants. It is accepted that burning of the cut vegetation before cultivation gives rise to increased yields. The nutrient value of the ash is probably only one of several factors involved. Dr. Bunting stressed the need for further analysis of the function of bush fallow in restoring productivity. Recent work in the Sudan suggests that a type of erosion described as 'surface wash' of the exposed soil may be one reason for the rapid decline in productivity of tropical soils after the bush canopy has been removed. Under these conditions, the top few inches of the soil which may contain the bulk of the accumulated fertility can be washed away.

Modern methods of farming often demand a different type of clearing, involving the complete and large-scale removal of stumps and roots of the existing trees and bushes. Such large-scale clearance schemes are likely to include the following phases : survey of the area by aerial photography and ground observations, followed by the preparation of detailed soil and vegetation maps; production of a land utilization and conservation policy and construction of access roads and labour camps; cutting of the vegetation; disposal of debris ; removal and disposal of stumps; and installation of soil conservation works. 


\section{№. 4419 July 10, 1954}

An informative analysis was given of the different methods of bush-clearing employed in the Groundnut Scheme in Tanganyika, together with the costs of each operation. Much of the heavy equipment, particularly that used for the removal of roots, caused severe damage to the soil, and the current view is that lighter implements should be used wherever possible. Dr. Bunting concluded by saying that it is not generally appreciated how much detailed information on the bush-clearing techniques had been obtained in Tanganyika and that this information would be of great value in the planning and execution of clearing projects.

The second paper, entitled "The Present Role of Arboricides in Bush and Forest Clearance", was given by Mr. J. D. Fryer, of the Agricultural Research Council Unit of Experimental Agronomy, University of Oxford. The paper was in two parts. The first section reviewed the dovelopment of chemicals for killing individual trees or scrub either by individual treatment or by overall spray application. The second part summarized some work on arboricides carried out in Tanganyika and Kenya by members of the Unit of Experimental Agronomy working in conjunction with various organizations in East Africa.

Of the many chemicals that have been tested, ar'senical compounds have proved to be by far the most successful, and they are at the present time widely employed in forestry and plantation work for the local trea.tment--in frill girdles, bark notches or auger holes-of unwanted trees. There is, however, a definite need for non-poisonous substitutes, and much work has been done during the past ten years in an attempt to find materials that are both efficient and safe. The most promising is undoubtedly ammonium sulphamate; but the synthetic growth regulators 2,4-dichlorophenoxyacetic acid $(2,4-D)$ and $2,4,5$-trichlorophenoxyacetic acid $(2,4,5-\mathrm{T})$ have also given good results when applied in the same way as arsenical compounds, particularly with smaller trees. These phenoxyacetic acids also show promise when applied in an oil carrier to the bark of the trunk as a basal band of one or two feet. This treatment in effect 'girdles' the stem by killing the bast and cambium and may also destroy dormant buds, thus preventing or reducing regeneration.

During the past few years considerable advances have taken place in the destruction of bush or scrub by arboricides. Extensive areas of scrub along roadsides, under power and telegraph lines and in grassland are being sprayed each year in the United States and Canada with good results ; this practice is being developed in other countries, particularly New Zealand. The chemical most commonly used for this work is 2,4,5-trichlorophenoxyacotic acid, generally as a long-chain ester, applied either alone or mixed with 2:4-dichlorophenoxyacetic acid. For overall applications from the ground, oil/water emulsions are often applied in a relatively high volume per unit area; but when application is made by aircraft more concentrated oil solutions or emulsions are employed. Ammonium sulphamate in an aqueous solution is also being widely used as an overall application from the ground.

The investigations in East Africa have been mainly of two types: the development of arboricides for the control of regenerating bush of the types found in tsetse-fly barrier clearings in Tanganyika, or for the destruction of Isoberlinia-Brachystegia bush in Nyasaland, which is characteristic of large areas where shifting cultivation is practised by the natives; and secondly, the testing and assessment of the value of chemicals as defoliants of woodland as an aid to tsetse-fly control. The results to date of spraying regenerating bush indicate that a complete kill is unlikely to be obtained with the existing arboricides because they are not transported in toxic quantities to the roots and because the species which are adapted to frequent cutting and firing sucker freely from the roots. The overall spraying by aircraft of the butyl ester of 2,4,5-trichlorophenoxyacetic acid on to an area of forest in Kenya resulted in defoliation and death of a great many woody species, including large Ficus trees and two succulent species of Euphorbia. The role of a defoliant in increasing the light intensity and thereby allowing the rapid growth of the grasses during the rainy season was of particular interest, since a normally unburnable vegetation was destroyed by fire during the following dry season. Further work on arboricides in East Africa is now being carried out in conjunction with the Unit of Experimental Agronomy at Oxford.

After a short discussion, the meeting was closed by Sir Harold Tempany, who said that there is no doubt that, if world food production is to keep pace with the increasing population, extensive clearing of land will have to be undertaken prior to agricultural development and that the techniques and principles of bush and forest clearing discussed during the meeting are likely to have a very real value.

\section{SOUTH-EASTERN UNION OF SCIENTIFIC SOCIETIES}

\section{ANNUAL CONGRESS}

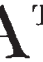

' $\mathrm{I}$ the invitation of the Maidstone Scientific and Antiquarian Society and the Mayor and Corporation of Maidstone, the South-Eastern Union of Scientific Societies held its fifty-ninth annual congress at Maidstone during Jume 10-13 under the presidency of Dr. Glyn Daniel. 'The local committee for the Congress was under the chairmanship of Sir Garrard Tyrwhitt-Drake, with L. R. A. Grove as local secretary. At the young naturalists' evening Maxwell Knight lectured on "The Hand Rearing of a Cuckoo", illustrating his remarks with lantern slides.

The presidential address to the Archæological Section, on "The Present State of Monastic Archrology in Kent", was given by F. C. Elliston Erwood, who dealt with the development of monastic buildings, using Kentish examples to illustrate his points. In mentioning the difference between usual monastic buildings and those of orders of military origin, he emphasized the scope for the examination of the latter within the county. G. E. Newell gave the presidential address to the Zoological Section, his subject being "Animal Zones of the North Kent Coast". He said that the physical environment, the exposure of animals for long periods by tidal action twice daily and large thermal differences demand a toughness in the faunal population. The direction of the beach drift is from east to west, opposite to that often suggested as existing in the Thames Estuary.

Dr. Glyn Daniel's presidential address to the Union was on "The Art of the Megalith Builders". He commenced by saying that although Stonehenge had been examined and studied for a great number of years, it had only recently bcen noticed that some 